

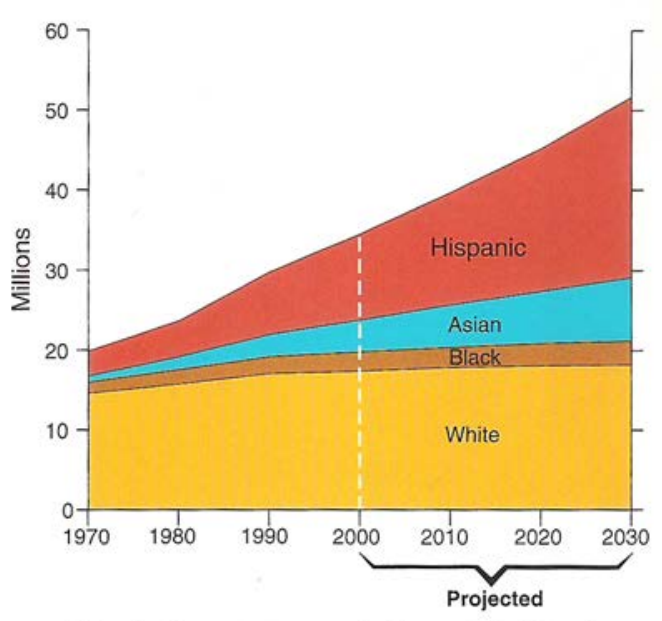

Fig. 1 Changing population of California. Source: California Department of Finance, Demographic Research Unit, 1998.

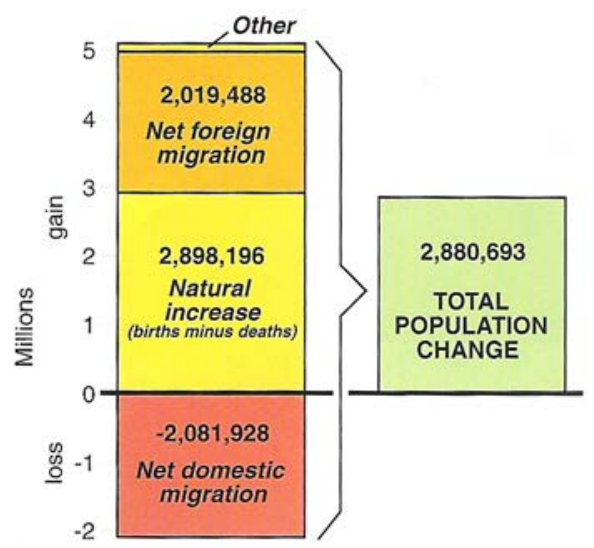

Fig. 2. Sources of population change in Californla, 1990-1998. Source: U.S. Census Bureau.

changes affect the state as a whole and the agricultural community in particular? What are the implications for the counties that serve as the fruit and vegetable basket of the United States?

The United States is, of course, a nation of immigrants, and California is no different. The American economy, culture and political structure have long been defined and shaped by waves of new residents from Europe, Africa, Asia and Central and South America and elsewhere. Like all previous waves, the current flow of immigrants to California will change the social and occupational structure of the state and provide new opportunities and challenges.

\section{The growth process}

Rapid population growth is not new to California. The state grew rapidly with internal immigrant waves in the 1920s and 1930s, and again after World War II, when a westward migration transformed the state into the most populous in the nation. Since the Hart Cellar Act of 1965 transformed immigration laws, California has received a large number of new $\mathrm{mi}-$ grants; the foreign-born population has grown from less than a million in 1970 to almost 8 million in 1998.

The state grew by almost 15 million people between 1970 and 2000, more than $70 \%$ (fig. 1). Between 1990 and 1998 alone, 2.88 million people were added. That growth includes a net inflow of a little more than 2 million international migrants (fig. 2), as well as 4.7 million new births. The total natural increase (births minus deaths) of 2.9 million is actually greater than the total increase in the state. However, California also experienced net domestic out-migration of over 2 million in the 1990 s, resulting in total growth of approximately 2.88 million people through July 1998.

Proportionately, new immigrants provided $74 \%$ of the net growth of California's population. Much of the natural increase is due to the higher fertility rates of the new immigrant population. About half of all births in California are to foreign-born mothers (Clark 1998). The domestic outmigration from California during the 1990s was related to the downturn in the state's economy early in the decade. Changes in domestic migration are quite susceptible to economic changes and thus will rise and fall with the state's economic trajectory.

Overall, it is likely that the growth of the past 30 years will continue in the coming decades. Immigrants are still coming to California, and there is no sign that the flows will slow in the next two decades, even though increased border enforcement is making it more difficult to make the passage. Moreover, research shows that there is less circular migration than there was 40 years ago (Binational Study 1998). More people are coming and fewer are returning to Mexico and other Central American nations.

Current migration is a function of previous migration; it is a selfperpetuating process. The migrants who came earlier and stayed set up a social world for future waves of $\mathrm{mi}$ grants, especially now that family reunification is a major part of the legal immigration process. Because migrants have increasingly dispersed throughout California, their populations will increase not only in the large urban areas, but also in the rural towns and cities. This population growth will have important implications for rural communities in the 21st century (Medvitz 1998).

State demographers now predict that California will grow to almost 52 million people by 2030 (California Department of Finance 1998). That growth is more than the current total population of the five-county Southern California region, and it will be very different in composition. Projections by the State Demographic Unit suggest little change in the size of the nonHispanic, white population, but a significant growth of the Hispanic and Asian populations.

Therefore proportions of the nonHispanic, white population will decline in relation to the entire population (fig. 1). However, as time goes by and intermarriage increases, the number of mixed-race/ethnicity families will increase. It will be more difficult to speak of Hispanic or Asian households. In addition, the new "check all" self-identification in the 2000 census will create a much more complex structure of self-reported ethnic groupings.

During the first few years of the new millennium, California will no longer have a white non-Hispanic majority, and by 2030 almost $44 \%$ of the population will be Hispanic. Asians and Hispanics together will make up more than two-thirds of the state's population, a change in ethnicity that will alter the enrollment of schools and colleges and instigate changes in political representation as these new groups participate more actively in the political process. 


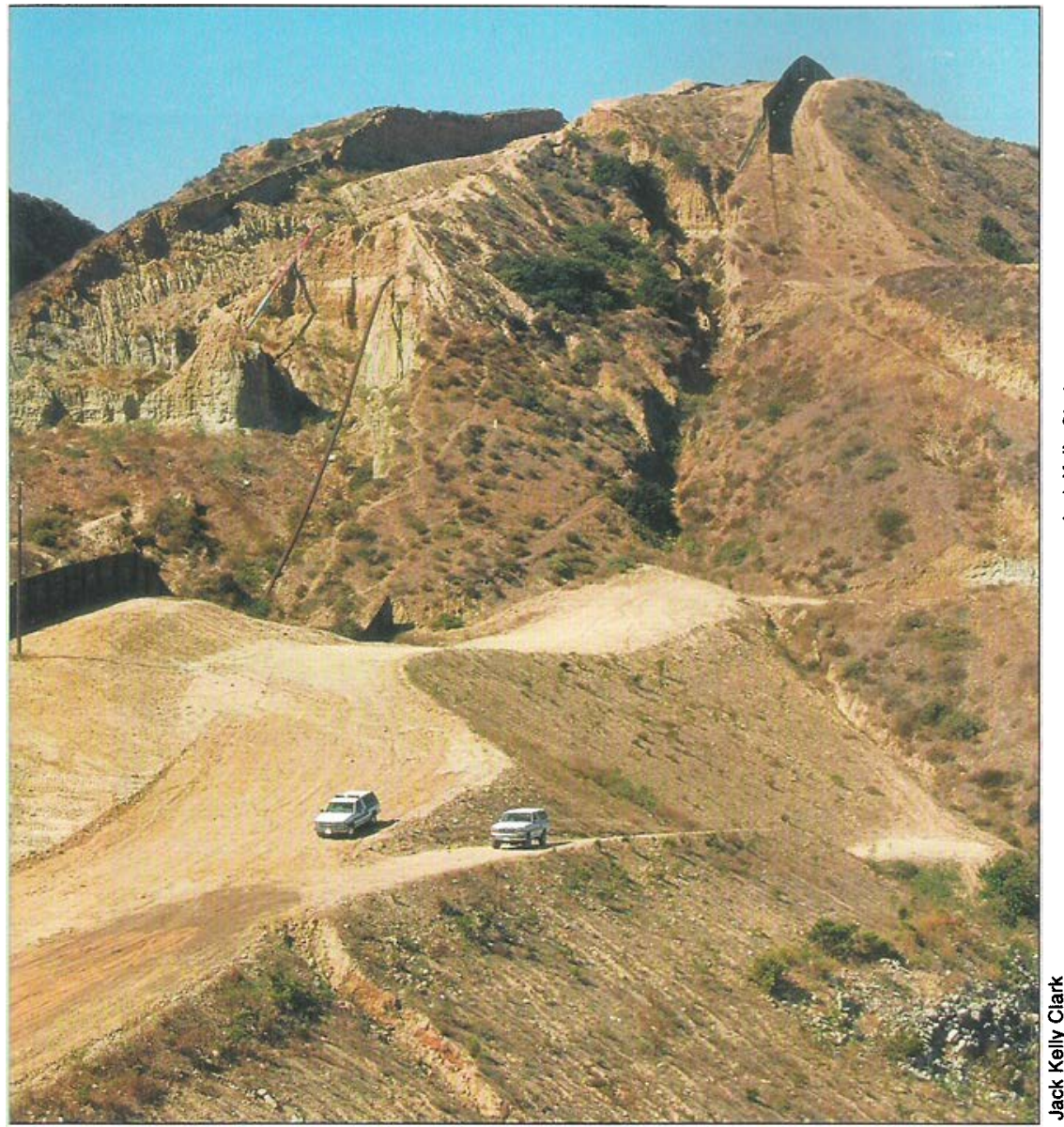

Control efforts have increased along the U.S./Mexico border, such as top right, where a wall faces Tijuana housing, and above, where border vehicles patrol a fence near San Ysidro. There are few signs that immigration to California will slow significantly in coming decades.

\section{Aging and fertility}

The coming changes can be traced to different age/sex pyramids and fertility differentials of the white, black, Asian and Hispanic populations of the state. The pyramids, which show absolute numbers in age categories for these groups, reveal striking contrasts between the white and Hispanic populations, California's two largest groups (fig. 3). The white population pyramid shows clearly the baby-boom population, now approximately 35 to 55 years old, and the baby-boom echo, between 5 and 19 years old. The graph also shows that the white population is aging rapidly, with large proportions of retirement-age men and women, especially the latter. The graph is quite unbalanced in the older-age female categories. The white population

pyramid is beginning to show the classic rectangular pattern of advanced information societies, where the youthful and older populations are nearly equal.

yramid is much more youthful, with the diagram more nearly a true pyramid. The large number of very young children, under 9 years of age, is nearly half again as large as the white population, and it is not difficult to envision how this very young population will translate into future increases in the Hispanic population. The average fertility of Hispanic women in California is about 3.5 children, and it is higher for Hispanic women with less than a high-school education. Relatively high fertility, large numbers of young women

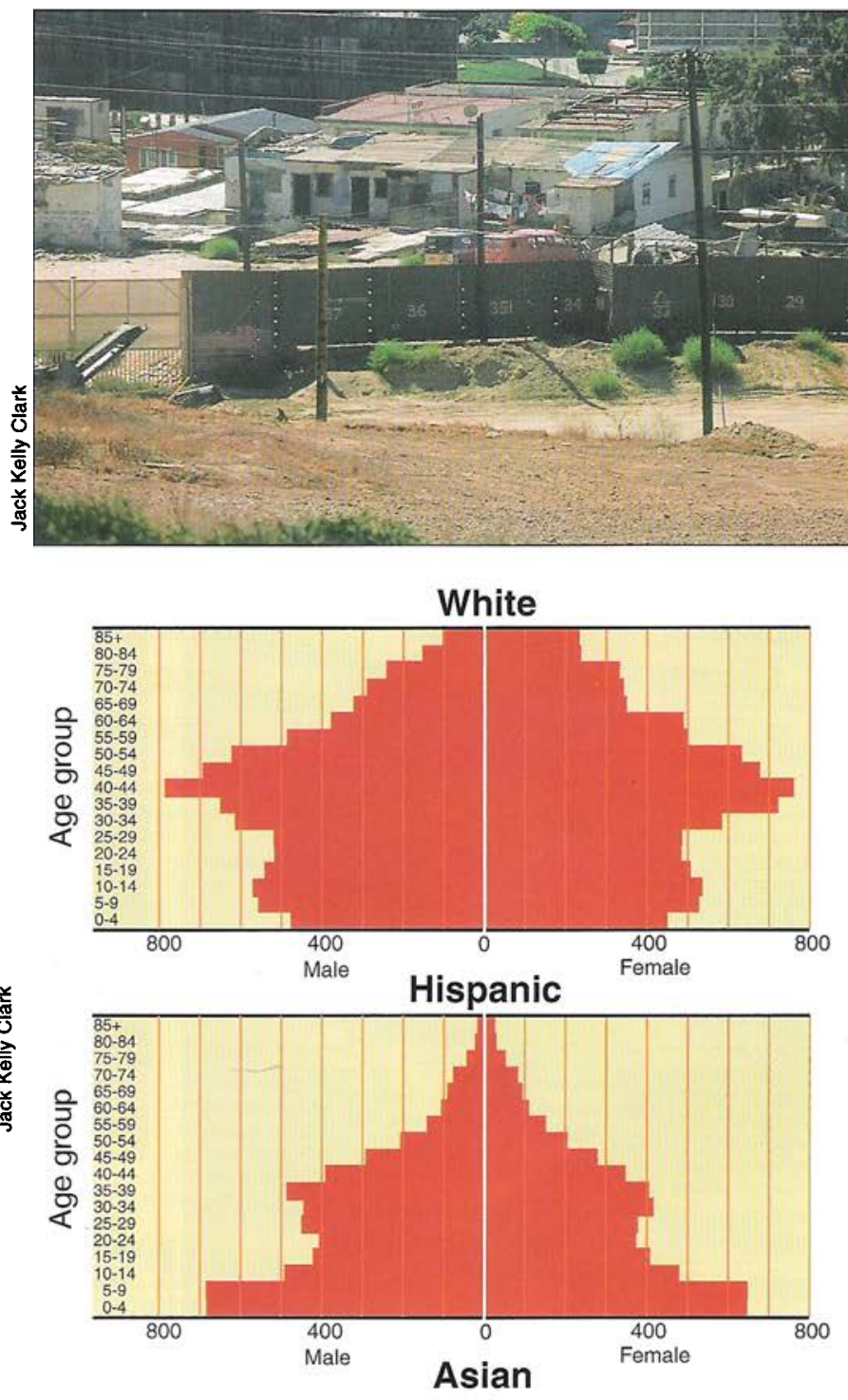

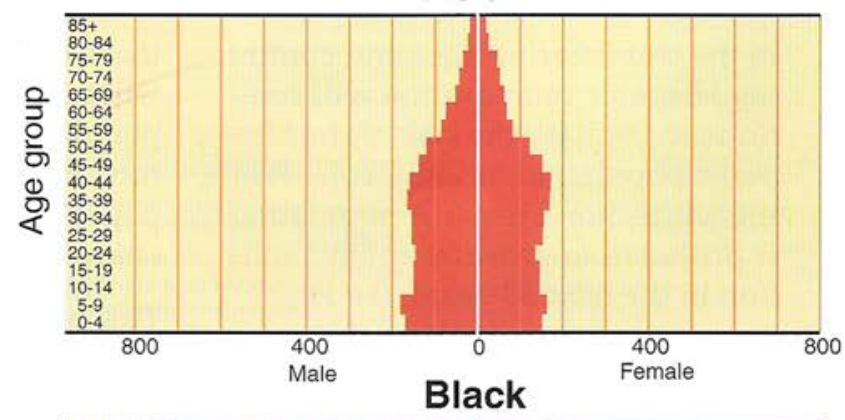

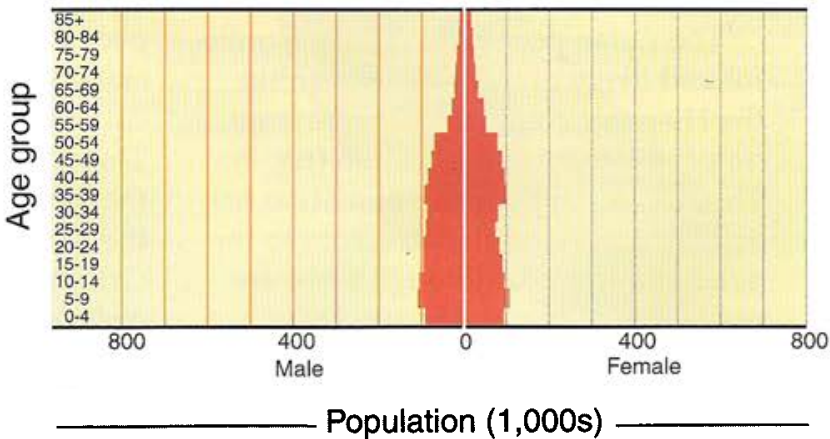

Fig. 3. Age-sex pyramids of projected populations in 2000 by ethnicity in California. Source: California Department of Finance, Demographic Research Unit, 1998. 


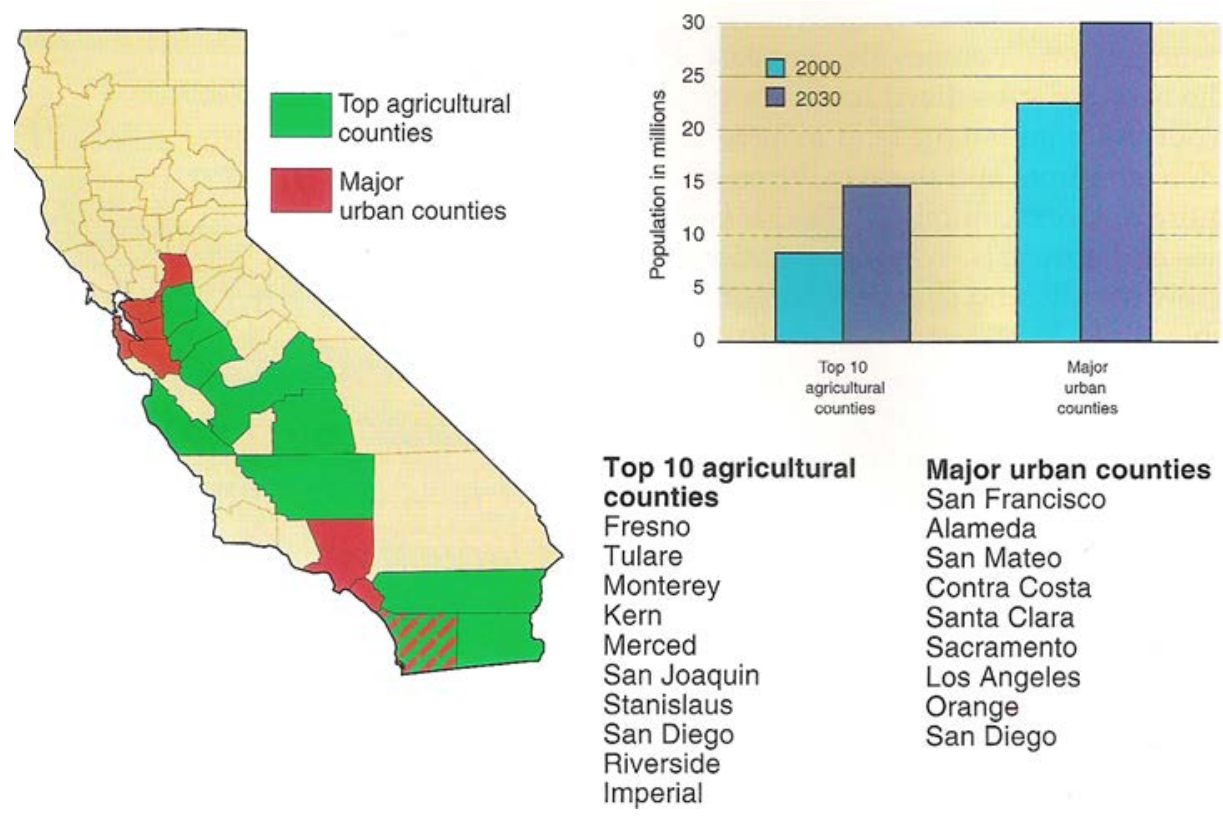

Fig. 4. Projected population change 2000-2030 in California counties. Source: California Department of Finance, Demographic Research Unit, 1998.

rural contexts and increase the deconcentration of the metropolitan population in California.

Much of the growth that is occurring in the Central Valley, especially in the corridor between the Bay Area and Sacramento, and in the northern San Joaquin Valley, is spillover into formerly agricultural land. Bay Area commuters and other newcomers are moving into new housing developments that are springing up in suburbs within long-distance driving of urban employment centers. A similar process is occurring in San Diego County along the corridor from San Diego to Los Angeles and in the interior valleys along Interstate 15 between Riverside, Escondido, Temecula and San Diego.

The changes in the composition of the population will affect smaller communities too - it will not be only a big-city phenomenon. Many counties and their cities will be ethnic pluralities (that is, there will not be a dominant ethnic group) by the end of the next decade. In 1990, only Los Angeles County had an ethnic plurality, but in the coming decade ethnic pluralities will cover a broad band of counties from Riverside to the suburban counties of the Bay Area (fig. 5). All of the southern San
Joaquin Valley will be an ethnic plurality by 2010 .

Social and cultural changes will accompany California's growth in size and ethnic diversity. For example, Hispanic immigrant neighborhoods often develop amenities such as soccer and social clubs, which in turn make them more like home for prospective migrants. This is a sign of the ability of new immigrants to create a social world for themselves and their children in their new homeland.

Equally important, the political landscape will change as candidates consider a diverse population with different needs from those of the formerly majority white population. There is a growing dynamism between immigration and social and cultural change, and the population mixing that was once more obvious in some large inner-city communities will soon be the norm for a sweep of communities across California. Even though there were always ethnic neighborhoods in the towns and cities of the Central Valley, the look and feel of neighborhoods, and the issues that have been central in multiethnic counties like Los Angeles, will become more common in the neighborhoods of Fresno, Stockton, Modesto and Visalia.

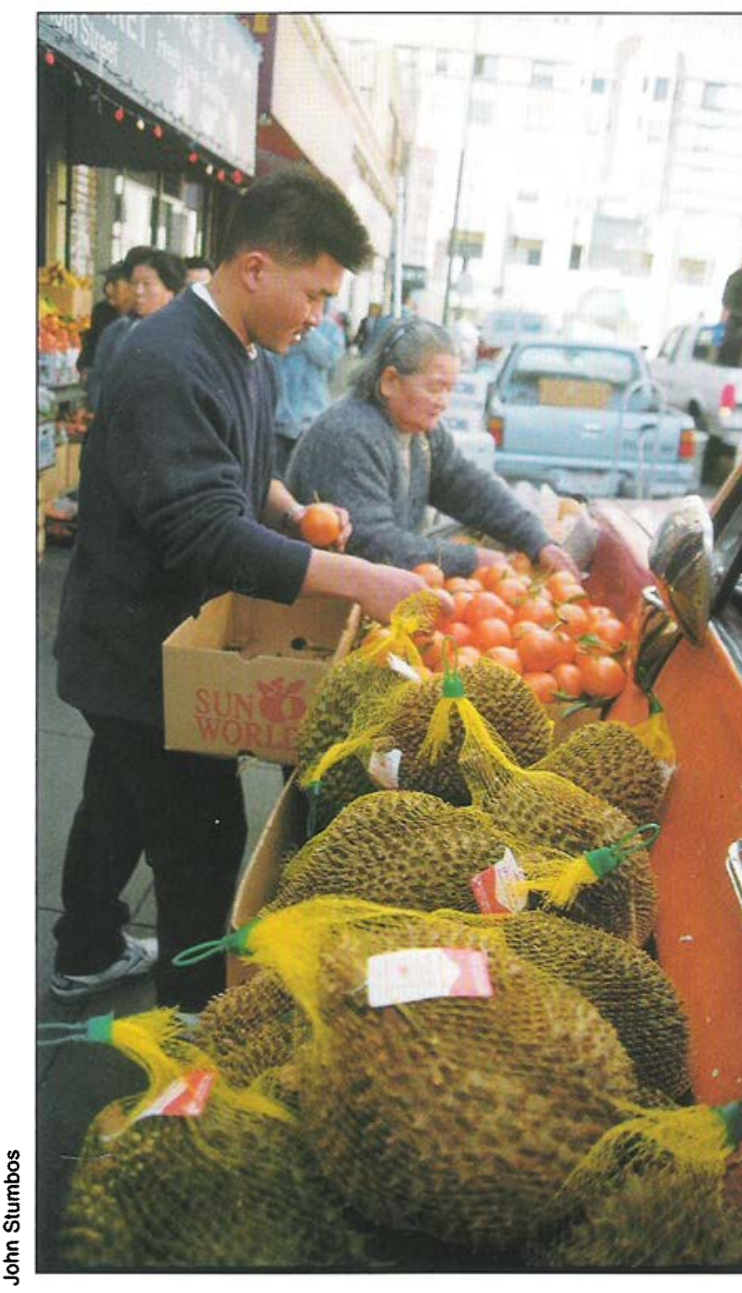

Oakland's Chinatown is truly Pan-Aslan, with multicultural residents from China, Taiwan, Vletnam, Cambodia, Korea and other countries.

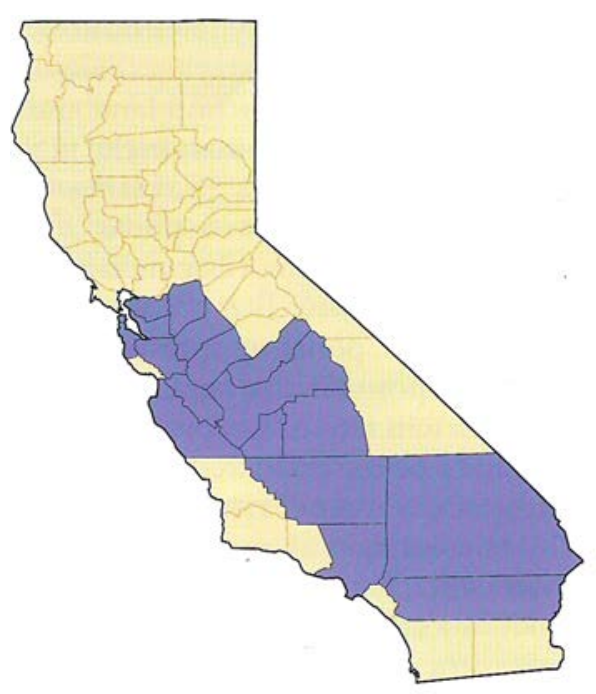

Fig. 5. Counties with an ethnic plurality in 2010. Source: Callfornia Department of Finance, Demographic Research Unit, 1998. 


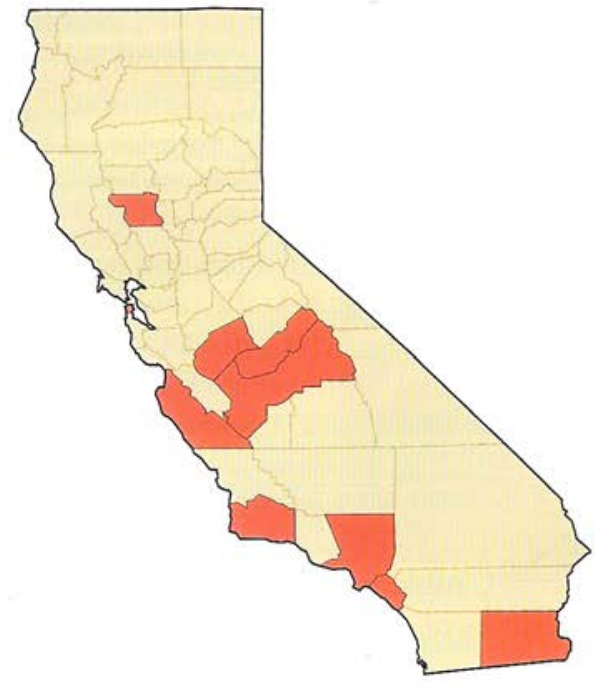

Fig. 6. Counties that have greater proportions of students with limited English proficiency than the California average in 1998-99. Source: California Department of Education, 1999.

Housing. Increases in population create needs for housing and other elements of shelter infrastructure, from sewers to streets. Because there is very little public housing in California, housing provision has been and still remains a private-sector activity. Given a rapidly increasing low-wage population in a state with relatively high housing costs, there are bound to be stresses in the system. Anecdotal reports document overcrowding and inadequate housing across a wide range of contexts, but nowhere more dramatically than in the agricultural regions of California's Central Valley. Migrant workers, who follow the harvests, are often crowded 10 to a room in cheap motels. The federal Commission on Agricultural Workers estimates that nearly a third of California's farmworkers lack adequate shelter (New York Times, May 31, 1998)

The Statewide Housing Plan Update estimated that California had an annual need for more than 200,000 units during the 1990s, but produced only a little over 100,000 units annually (California Housing Resource Center 1998). The greatest shortfall has been in the production of multifamily housing. The gap between housing demand and housing production has cre-
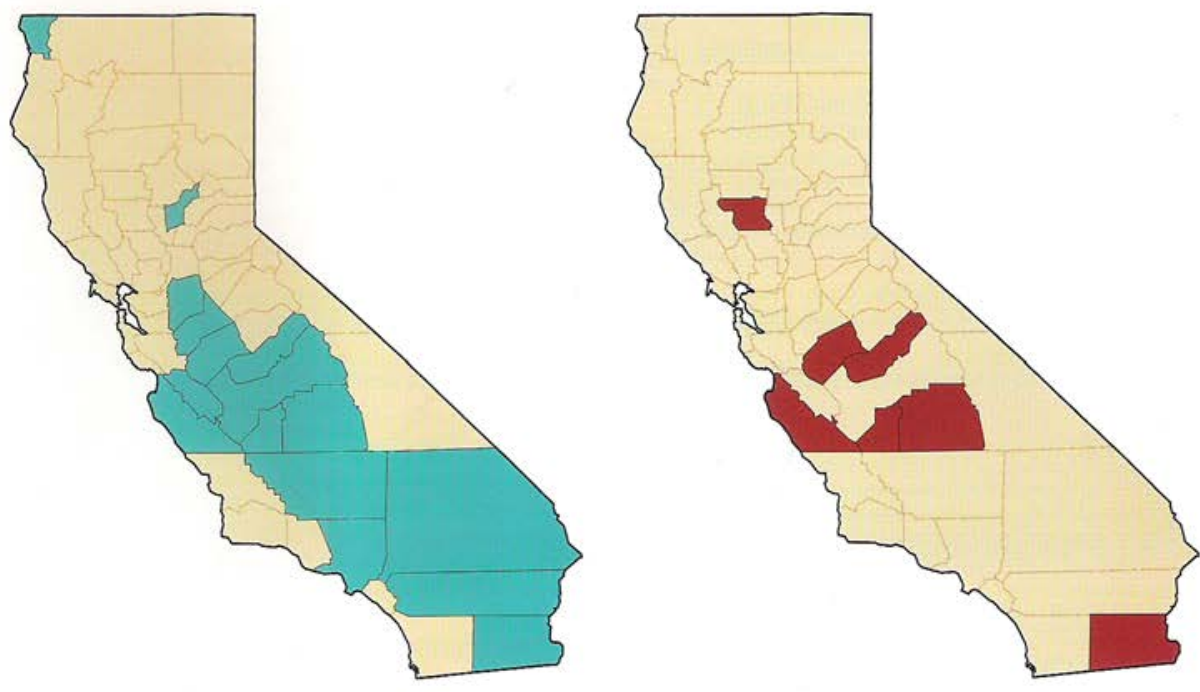

Fig. 7. Counties that exceeded the California-wide teenage pregnancy rate in 1997. Source: California Department of Health Services, 1999a.

ated greater housing cost burdens, especially in the major metropolitan areas, where rents increased by $20 \%$ to $35 \%$ between 1995 and 1997.

Nearly half of all renter households in California paid more than $30 \%$ of their income for housing; among poor renters, $63 \%$ paid more than $50 \%$ of their income for housing (California Housing Resource Center 1998).

Along with problems of affordability, there are increasing problems of overcrowding, especially for lowincome Hispanic households, which account for more than three-quarters of all severely crowded households. Overcrowded units often have problems and require rehabilitation. Statewide, about $12 \%$ of the housing stock is substandard, but that figure rises to between $20 \%$ and $25 \%$ for much of the Central Valley housing stock.

\section{Future in focus: Policy debates}

The changes occurring in California are connected to worldwide changes in immigration and globalization (Clark 1998), which are similar to those in a wide variety of other countries and states. The changes occurring now, and those expected in the next three decades, are related to continu-
Fig. 8. Counties that have rates of Medi-Cal-funded deliveries $\mathbf{5 0} \%$ greater than the California average in 1997. Source: California Department of Health Services, 1999b.

ing high levels of legal and illegal immigration, to the demand for lowwage labor by industrial and agricultural entrepreneurs in California, and to the lack of a consensus on a population policy for the United States as a whole. The outcomes are altering local social and economic contexts and are imposing considerable burdens on some local governments (Clark 1998).

There is no evidence, given current legal admissions of almost 1 million people per year to the United States, that the California population will slow its growth even after 2030. Although it is expected that the current high fertility of the new Hispanic population will decrease, even modest fertility levels will continue to increase the Hispanic population. In addition, Mexico will grow to about 150 million by the middle of the next century, putting pressure on job provision within Mexico and motivating young workers to look for work in the United States. Given current conditions in Mexico, it is not at all clear that Mexico will have sufficient job growth for its expanding population. We can expect continuing flows whether there are jobs in California or not.

The population growth in traditionally rural counties has increased pres- 


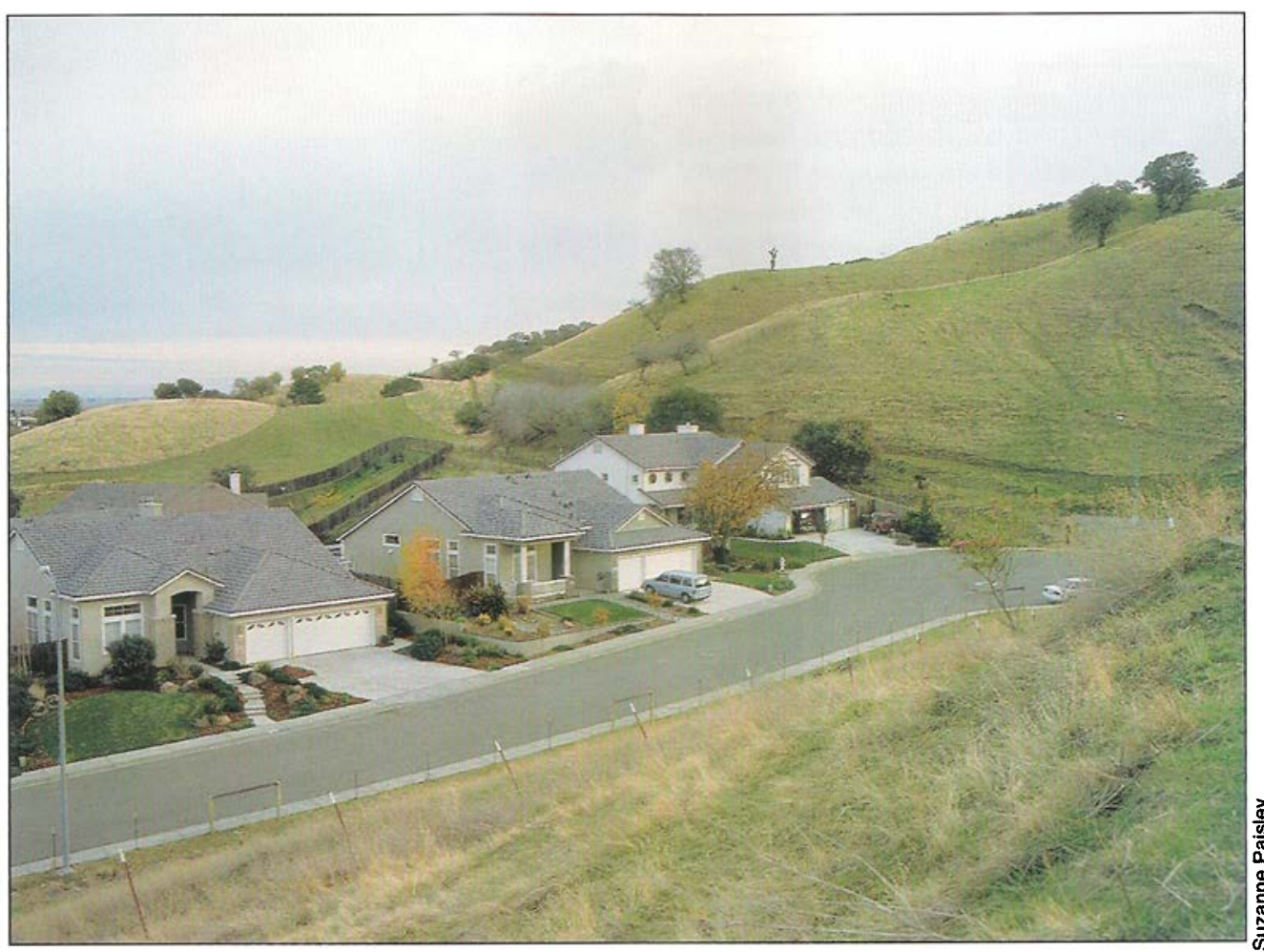

Low-income and publicly funded housing are hard to come by in California, while private-sector builders cater to middle- and upper-income buyers. One-third of the state's farmworkers lack adequate shelter.

sure to control "sprawl" and limit farmland conversion to urban uses (Sokolow 1998). Californians are struggling to balance the growing demand for housing with the need to protect natural resources and agriculture. In the absence of regional or statewide land-use policy, land-use decisions are fragmented, as illustrated by growthcontrol proposals in some communities coexisting with virtually unregulated growth in others. Finding a balance between demands for housing and protecting California's agricultural and natural resources will take place amid expanding concern over local growth-control proposals. The recent decision of the Packard Foundation to fund farmland purchases is a sign of the renewed focus on urban growth and urban encroachment (Los Angeles Times, Oct. 24, 1999). As already demonstrated, nowhere is this more apparent than in the Central Valley.

The flows of undocumented migrants will not decrease either. Current estimates from the U.S. Immigration and Naturalization Service's Office of Policy and Planning suggest undocumented flows of about 275,000 per year to the United States. About half are from Mexico, and the majority enter through California even if they do not stay in the state. Some sense of the pent-up demand for entry to the United States is contained in the waiting lists for visas. In 1997 there were more than a million Mexican nationals waiting for visas to the United States (Clark 1998). Moreover, where once the flow of undocumented immigrants was largely male and youthful, the flow now includes many more families and women.

California in the next two to four decades will undergo changes that are not dissimilar to earlier periods of rapid growth in California history. The issue is how to incorporate and empower these new Californians. Although many new immigrants bring needs for additional resources, they are also a large proportion of the California labor force, and they provide much of the low-wage labor for the low-cost services that Californians enjoy on a daily basis. In addition, ethnic diversity continues to enrich the state, both culturally and socially. At the same time, the state would be amiss if it did not recognize that a significant proportion of the new immigration population is struggling with low incomes and limited opportunities.

The question for California now is how to invest in education and social services to ensure that the new flows into the state enrich California just as earlier waves set the stage for today's social and economic advances.

W.A.V. Clark is Professor of Geography, UC Los Angeles and author of The California Cauldron: Immigration and the Fortunes of Local Communities.

\section{References}

Binational Study. 1998. Migration between Mexico and the United States. Washington, DC: US Commission on Immigration Reform. $93 \mathrm{p}$.

Bouvier LF. 1991. Fifty million Californians. Washington, DC: Center for Immigration Studies. $93 \mathrm{p}$.

California Department of Education, Educational Demographics Unit. 1999. Limited English proficiency students by county, 19911998. Sacramento, CA.

California Department of Finance, Demographic Research Unit. 1998. Race and ethnic population, age and sex detail, 19702040. Sacramento, CA.

California Department of Health Services. 1999a. County health status profiles. Sacramento, CA.

California Department of Health Services. 1999b. Medical care statistics. Sacramento, $\mathrm{CA}$.

California Housing Resource Center, Department of Housing and Community Development. 1998. California's housing markets, 1990-1997. Sacramento, CA.

Clark WAV. 1998. The California Cauldron: Immigration and the Fortunes of Local Communities. New York: Guilford Press. $224 p$.

Cohen J. 1997. How Many People Can the Earth Support? New York: W.W. Norton. $532 \mathrm{p}$.

Garreau P. 1991. Edge City: Life on the New Frontier. New York: Doubleday. 548 p. McCarthy K, Vernez G. 1997. Immigration in a Changing Economy. Santa Monica, CA: The RAND Corporation. $338 \mathrm{p}$.

Medvitz AG, Sokolow A. 1995. Population growth threatens agriculture, open space. $\mathrm{Cal}$ Ag 49:11-7.

Medvitz AG. 1998. Urban growth squeezes agriculture. Cal $\mathrm{Ag} \mathrm{52:8-10.}$

Sokolow A. 1998. North Bay leads Central Valley in protecting farmland. Cal $\mathrm{Ag}$ 52:17-22.

Taylor E, Martin P, Fix M. 1997. Poverty Amidst Prosperity: Immigration and the Changing Face of Rural California. Washington, DC: The Urban Institute Press. $125 \mathrm{p}$. 